\title{
The Many Streams in Ralph Pred's Onflow
}

Anderson Weekes ${ }^{1}$

While making no special claims to originality, Ralph Pred's Onflow manages to be so unique that it seems to come out of nowhere. ${ }^{2}$ Pred does not hail from, advocate for, or associate himself with any already allied group of intellectuals with a banner or an ax, and although his book is professedly a study in Whitehead's philosophy, it has little in common with contemporary Whitehead scholarship. Only fourteen of the one hundred eleven authors named in his bibliography are Whiteheadians, and while he takes cognizance of important monographs by process philosophy's prominent scholars, it is significant that he makes not a single reference to the journal Process Studies. I make this observation not to diminish the importance of Process Studies, which has become an invaluable resource for us all, nor to suggest that Pred's scholarship is wanting, but to underscore that his motivations are not intramural. This book speaks directly to nonWhiteheadians-to analytic philosophers, to cognitive psychologists, to phenomenologists, and to neurobiologists. And Pred puts their probably well-justified fears to rest: yes, it is possible to find Whitehead's ideas useful, even compelling, without first undergoing a conversion.

\section{Aims, Methods, and Exclusions of Pred's Project}

For want of a better name, synthetic scholarship is the genre to which I would assign this book. Synthetic scholarship does not claim to offer an original theory, but an original synthesis. Typically it brings together theories that were unrelated in their conception and continue to be unrelated in the critical literature. It seeks to show how they are mutually relevant and can be used to interpret, supplement, correct, or articulate one another. In this case, the theories in question are, in the order of their staged implementation, those of William James, John Searle, A. N. Whitehead, and Gerald Edelman, with a surprising touch of Martin Heidegger deployed where one would least expect it.

Pred's aim is a general theory of consciousness: its phenomenology, a theoretical explanation of that phenomenology (a model), and a possible neurobiological basis for the phenomenology thus explained (a physical 
interpretation of the model). To many it will come as a surprise that he thinks Whitehead's metaphysical categories can be fruitfully recruited for this project. Even a sympathetic reader must find not a few of Whitehead's signature ideas far-fetched. So it cannot be stressed enough that Pred does not validate Whitehead's ideas by stipulating criteria for theoretical adequacy that only Whiteheadians would accept.

Pred begins with an analysis of James' psychology and his later philosophy of radical empiricism. He considers James' description of the stream of consciousness to be the high-water mark of phenomenological accuracy, and it remains the evidentiary touchstone for the whole of his project. This analysis of James is rich enough to stand on its own as a scholarly achievement. For example: It is not obvious to readers of James how some of his key notions are meant to fit together. Among these are the phenomenologically crucial concepts of the "fringes," the "transitive parts" of the stream, and the "co-conscious transition." Pred provides a subtle and coherent reading that establishes precise descriptive connections among these concepts. Important to the early stages of his project is what these concepts all have in common: they are all aspects of the intentionality of consciousness. Pred finds that James' analysis is weak in delineating the logical structure of this intentionality, just as Searle's analysis of intentionality, while strong on its logical structure, is weak at delineating its temporality. Pred is able to establish a sufficiently tight fit between operative concepts in the two thinkers to be able to embed Searle's theory of intentionality into James' stream. Pred then proceeds to show how the resulting description of consciousness exemplifies Whitehead's categories. This has a double benefit, giving Whitehead's categories an evident empirical application at the same time that it establishes a theoretical model of consciousness. In the last chapter of this always surprising book, Pred executes a not implausible mapping of the operative concepts of his Whiteheadian model of consciousness onto Gerald Edelman's neurobiological theory of consciousness. His objective here is not to embrace Edelman's theory, but to show that the physical realization of the Whiteheadian model of consciousness is possible from an informed natural scientific standpoint.

Before turning to Pred's constructive arguments and interpretations, decisive qualifications need to be acknowledged. Pred is here interested in Whitehead's metaphysical categories insofar as they can be used to construct an empirical model of consciousness. He does not commit himself to a defense of Whitehead's metaphysics tout court. In a gesture that may well alienate some of Whitehead's most ardent supporters, he brackets, for example, the whole of Whitehead's theology. And wherever Whitehead's theory of consciousness seems to depend on hyper-empirical concepts, such as "eternal objects," their "primordial valuation," or the divine bestowal of 
an entity's "subjective aim," Pred argues that the concepts in question can be given what he calls a "naturalistic" interpretation (pp. 171-81).

Some of Whitehead's apologists will be puzzled by this project because they think the virtue of Whitehead's philosophy is that it offers a theology, a metaphysics, and an epistemology that are already fully naturalized. It is, they allege, only because we refuse to let go of a long-ago discredited "mechanistic" concept of nature that Whitehead's metaphysics seems to us "supernatural." But any reader of Process and Reality can see that there is some equivocation going on here. If the theory of Process and Reality is "natural," then we are using the word "natural" in a $17^{\text {th }}$ century sense (as in lumen naturale, where "natural" really means "rational" as opposed to "positive" or "revealed"). To defend Whitehead's metaphysics as natural in this sense misses the critics' point, which is that Whitehead's speculative philosophy does not honor the maxim of his earlier logical and natural philosophy: where possible, to replace inferred theoretical entities with logically equivalent constructions from items that are not inferred. In Process and Reality Whitehead would rather have maximum explanatory power than a minimum of theoretical entities, so he happily operates with concepts, like God's primordial valuation of the eternal objects, that have no empirical, phenomenological, or even anthropological content. What Pred tries to do is to make Whitehead's metaphysics conform to his earlier methodological maxim (pp. 174f.). This means, to the extent that it is possible, "logically reducing" the gargantuan theoretical entities of his metaphysics and, to the extent that it is not possible, showing that empirically we can get along without them (p. 172).

Pred definitely wants it both ways. Claiming that his "naturalized" interpretation of Whitehead is metaphysically neutral, neither presupposing nor excluding the extended, metaphysically transcendent interpretation of the system, he seeks to appease non-Whiteheadians without alienating Whiteheadians (p. 170). Whiteheadians will see that there is nothing neutral about this. It implies that everything transcendent in Whitehead's metaphysics is optional because empirically superfluous. Obviously this violates Whitehead's coherence requirement: a philosophical theory should be comprehensive and no part should be functionally independent of any other. 


\section{Role of Phenomenology in Pred's Investigation (and Its Unaddressed Snares)}

The fundamental challenge for any theory of consciousness, is, according to Pred, getting the phenomenology right. Like most writers who invoke the word "phenomenology", Pred believes that most accounts of consciousness go astray because they have failed to stay close enough to the relevant phenomena. Pred traces these failures to a familiar culprit-the adoption of an external standpoint toward something that can only be understood in the living of it. He refers to what James called the "psychologist's fallacy," which is to find in introspection only the objects that appear to thought rather than the whole of the thought to which objects appear (pp. 6ff.). Just as in language there are things that can be shown but cannot be said, so in thought there are things that are lived through, but cannot be thought about, and are therefore lost to objectifying description. Of prime importance here is thought itself, which, as James says, is never an object in its own hands. At the point where it has become an object, it is no longer the activity of thinking, but a passivity, being thought by a new activity of thinking into whose hands it has passed. There is a fundamental disparity between thinking as act and thought as its residue. Thinking is never thought, so the nature of thinking is not disclosed by thinking about it (p. 12).

The thinkable residues that objectifying reflection finds-seemingly waiting for it-are already abstractions, for they are precisely those parts of the stream that tolerate, in some sense, being arrested. By the same token they are divested of the very concreteness that characterized their functioning in the full context of the onflowing stream. Pred therefore identifies James' psychologist's fallacy as an example of Whitehead's "fallacy of misplaced concreteness" (p. 12). Being focused on the thinkable residues of thinking rather than on the experience of thinking itself, the psychologist mistakes an "intellectual, after-the-fact account" for the phenomenon itself.

As always, empiricism in general and Hume in particular are the targets of this kind of critique, predictably updated to include behaviorism and functionalism. Pred cites with approbation Chalmers' criticism of Dennett's Consciousness Explained (p. 7):

Dennett gives an account of consciousness that, as Chalmers notes, replaces the phenomenal seeming of things as the experiencing of them in a certain way with "a psychological sense of "seem" in which for things to seem a certain way is for us to be disposed to judge that they are that way." Consequently, Chalmers continues, Dennett's theory deals with 
judgments concerning phenomena rather than with the experiences themselves. In effect, Dennett is turning what he calls his "intentional stance" on his own stream of experience, repeating the withdrawal made by Hume and by Berkeley and others.

Since thinking is richer than thought, the critical question becomes: what does thinking have that thought does not? Seeking to account for the disparity between thinking as act and thought as its residue (the surplus in richness of the former over the latter) is what led James to the most celebrated discoveries of his psychology: the fringes and the transitive parts. Because it has strong methodological implications, it is James' distinction between the "substantive" and "transitive" parts of the stream of consciousness that plays the more conspicuous role in Pred's analysis. Substantive parts are elements that can be focused on, held in view, contemplated for some time. The transitive parts, by contrast, are by nature fleeting, incapable of being arrested and scrutinized, for any attempt to do so simply adulterates them into non-transitive parts with an entirely different nature and function. This famous distinction forms the basis of James' response to Hume's critique of causality. Hume claimed that he could not find causation or any similar relation between his ideas, to which James responded that Hume was looking in the wrong way for the wrong thing. Hume was practicing a kind of self-observation. But observation is a focal, fixating, and objectifying cognitive attitude. Turned back upon the mind itself, observation will never be able to find anything there but substantive parts (pp. 6, 46ff.). Since causality and other relations were not among the resulting inventory, Hume concluded that they were not there at all. But we have at all times a kind of non-observational awareness of what is going on in our experience, even if we cannot always subject it to the kind of sustained interrogation or forced introspection Hume insisted on (pp. 60ff., 94).

Pred thinks that an enlightened approach can avoid these fallacies of method, and his own approach is executed in a series of phases he calls "approximations," each of which is meant to draw up closer to the phenomena as they are, so to speak, "in themselves." The "James-based psychological approximation" introduces consciousness as the phenomenon delimited by the five universal characteristics famously identified by James. Because of its phenomenological accuracy, James' description "serves as a radically empirical baseline, imposing conditions of adequacy on any theory of consciousness" (p. 14). The "intentional approximation" draws on Searle, especially his book Intentionality, to exhibit the intentional structure of experience (pp. 14f., 55). The "processual approximation" draws on James to bring this intentional analysis closer to the phenomena by seeing how intentionality arises and functions within the stream (pp. 15f., 85). The 
"concrescual approximation" draws on Whitehead to see how this process looks not so much "up close" as "from the inside" (pp. 11, 16, 222). Finally, since this view from the inside still seems to presuppose a dichotomy between "lived (or phenomenologically described) from the inside" and "scientifically explained from the outside," along with the accompanying dualisms of mind and matter, subject and object, the "neurobiological approximation" is meant to move in the direction of a truly neutral monism where scientific explanation and phenomenology converge (pp. 16f., 282, 300ff.).

In the course of these approximations the reader cannot fail to notice the number of asseverations and strong assurances Pred gives that he is "stealing up" on the phenomena with a "gentleness" and "sensitivity" that "minimizes distortions" and renders "raw and unverbalized" experiences faithfully (pp. vii, 2, 6, 7, 12, 17-19, 84, 124, 198, 207, 243, 302, 315). Perhaps it is in the nature of phenomenology that it cannot give reasons for its truth. Precisely because its truth is phenomenological it must remain a private revelation, mute in its cogency. To become public it must simply appeal to the concurrence of others that things do appear to them the way they have been described, and Pred makes just this appeal: "At least, so it is for me, and you will have to judge for yourself" (p. 198). But if descriptions are phenomenologically perspicuous, why do we need to be assured and reassured that they are? At issue here is not a quirk of Pred's exposition, but fundamental questions about phenomenology.

Pred's method qualifies as genuinely phenomenological because of its systematic appeal to the phenomena only available to "non-observational awareness" (pp. 60ff.) The idea of non-observational awareness has played an influential role in philosophy since its unique systematic value was first brought to light in the late $19^{\text {th }}$ century. James was only one of a diverse group of thinkers, including Brentano, Bergson, and Husserl, who emphasized its importance as a source of crucial information-information that is easily overlooked precisely because it is not available in cognitively foregrounded ways. Ignoring its Continental background, Pred draws canonical testimony for the existence of such a thing as non-observational awareness from well-known discussions in analytic philosophy: Hampshire, Anscombe, Ryle. It suffices for Pred's purposes that "the answers to one's own or another's questions about our intentional states are available without observation, without directing awareness on the state" (p. 61).

The crucial idea is that there are deep truths whose availability depends on not trying to make them available in the customary ways. Drawing an analogy with quantum mechanics, we could speak of a "complementarity" between reflection and experience: certain fundamental properties of experience cannot be verified by reflection because reflection disrupts them. Now granting all this, shouldn't it puzzle us that the phenomenologist 
proceeds to do what he says cannot be done-reflect on the nature of these intimate experiences, objectify them, and make them available to public discourse? Phenomenological description seems to be predicated on its own impossibility. Perhaps this is going too far: phenomenological description is predicated on its own difficulty. This is a point that Pred concedes, indeed, that he stresses. But then we have a right to know by what criteria it is to be determined that we have surmounted, rather than succumbed to the inherent difficulties. At no point does Pred tell us why his descriptions succeed at being non-objectifying and non-falsifying, except to assure us that they are not.

The seriousness of this problem emerges from the fact that phenomenologists do not always agree. In fact, they don't always agree with themselves. Husserl took phenomenological inventory of conscious states and confidently claimed that there was no datum to be found there corresponding to the concept of the ego. He famously declared a decade later that he had found it. Most of his famous students and followers were sure he was mistaken in this later epiphany. Is the finding and not-finding of causality anything more than another case in point?

The fact that phenomenologists disagree about descriptive findings indicates a number of interesting things. First, it shows that they are assuming a uniformity of appearances from one descriptive vantage to another. Otherwise there would be no reason to disagree. After all, Husserl did not declare that an ego-datum had recently taken up residence in his consciousness, but that it had been there all along and he had missed it, just as his followers were sure he was seeing things, not that he had an ego, while they did not. It may be preposterous to doubt this uniformity assumption, but it is not clear what justification a phenomenologist could have for making it, and this should perhaps tell us something about phenomenology. In any case, given disagreement among phenomenologists, it follows from the uniformity assumption that deliberate exercises in phenomenology can be failures, that appearances can remain hidden, that descriptions can be unwitting fabrications. This raises the obvious question how we can know when we have succeeded in getting to the "real" appearances-to the "appearances in themselves." In this context we can appreciate attempts, e.g., by Husserl, to define an unambiguous methodological constraint. Pred's free-style approach does nothing to assuage skepticism, and in fact we will see that it allows inconsistencies and a measure of arbitrary confidence to pass unnoticed. Let's turn now to Pred's account of consciousness. 


\section{Pred's Interpretation of James: A Canonical Description of Consciousness}

Any adequate theory of consciousness must, according to Pred, do justice to the five characters of thought identified by James:

1. Every thought is part of a personal consciousness.

2. Thought is always changing.

3. Thought is sensibly continuous.

4. It deals with objects independent of itself.

5. It is more interested in some parts of its object than others.

Pred unpacks most of his phenomenology from the analysis of these five characters, which he returns to in each of his "approximations." His interpretation makes it clear, for example, how from the first character, along with the third, we can already derive what James describes as the budlike character of thought-the fact that it grows or progresses in drops or pulses (pp. 23f.). The "appearance of never-lapsing ownership" of the stream (1st character) is what is usually called self-consciousness. Examining the dyadic structure of self-consciousness, James found that there is at every moment an objective person known as "me" and an " $\mathrm{I}$ " doing the knowing. An intellectualist approach to consciousness sees the I as a persisting form and hence as the source of continuity and identity in the stream. But Pred agrees with James, who found that the Me is what establishes continuity because it is the cumulative record of one's experience. The I, on the other hand, is essentially evanescent because indistinguishable from its momentary performative actuality. This is a point upon which Pred lays great stress. The $\mathrm{I}$ is nothing but the activity of appropriating the $\mathrm{Me}$ adaptively in the novel context of the present. Now, however much in some purely objective sense the I may be said, by the psychologist for example, to belong to "me," this is not a datum of consciousness. The activity of the I cannot itself be appropriated as long as it is still appropriating. It is therefore only for a subsequent I that it comes to belong to the stream of personal experience, i.e., insofar as it is transformed into "me." This transformation happens inevitably because the $\mathrm{I}$ is the performance of a finite task (of appropriation), and once this task is performed and over it is no longer an I. Continuity ( $3 \mathrm{rd}$ character) requires that it become an addition to the Me, which is what happens to it when it is appropriated by a new I. This repeating cycle (thinking always becoming thought by a new thinking), which Pred calls the Me-I-Me "dialectic," is precisely the pulsed, bud-like character of the stream. The Me-I-Me dialectic, which lends itself to Whiteheadian interpretation (as the object-subject-object oscillation of 
becoming), is the key element in Pred's reading of James and the template for his own theory of consciousness.

Regarding the fourth character, Pred draws our attention to the importance of James' observation that it is only because we can mean the same thing with different parts of the stream that we come to think of what is meant as something existing outside of the stream (p. 34). This is phenomenologically important because meaning the same thing is one of the ways that adjacent buds can be continuous (p. 108). This will be critical to understanding the "co-conscious transition." The fifth character is crucial to the concept of fringe, and here Pred's reading of James as a phenomenologist proves especially rich. The fact that we are interested in some parts of an object more than others means that no topic of interest exists in isolation. There is always a fringe of further connection or relevance, however much it may be presently neglected, and it is precisely this fringe that marks out the possibilities for a progression of thought that is differently focused but not discontinuous (pp. 41f., 79ff., 92f.).

Pred's exposition reveals how much of James' phenomenology is implicit in the five-fold characterization: we can derive from it not only the fringed and bud-like character of thought, but also the existence and function of the "transitive parts." For the appropriation of the Me by the I is a process in which the I, not the Me, is taking definite shape. It is a process of subject formation, of transition to a fully formed thought (p. 24). Transition is therefore internal to the constitution of every bud. On the other hand, if thought is both bud-like and continuous, there must be transitions between the buds (pp. 46ff., 108ff.). Since each bud has a focus and a fringe of relevance that constitutes a range of possibilities for the inevitable continuation of thought, the crucial function of these transitive parts will be to maintain the focus across buds (the case discussed in detail below) or to transform some aspect of the fringe into a focus. Throughout, the Me functions as a ground of continuity against which the I achieves new focus relevant to present experience.

Beyond its coherence as an interpretation of James, the strength of Pred's analysis lies in his sensitivity to the way these transitions actually function. This enables him to identify characteristic distortions and omissions in descriptions of intentionality common in philosophical literature, which tends to take as paradigms of intentionality examples that are highly artificial: purposeless actions and purely passive perceptions. This results in models in which transition, causality, and temporal continuity play no significant role. Here is where Pred's critique and modified endorsement of Searle's theory of intentionality come into play. 


\section{The Revealing Gaps in Searle's Theory of Intentionality (and Some Gaps in Pred's Phenomenology)}

Like Whitehead, Searle defends the common sense view that causation, far from being something impossible to document, is ubiquitous and experienced all the time: whenever we perceive anything we are being causally affected by the thing we perceive, and we actually experience this causality in operation; whenever we act we are causally affecting our bodies and the world around us, and we actually experience this causality in operation. The validity of the common sense view emerges from his analysis of intentionality in perception and in action. In perception we do not simply intend something of such and such a description as being there, but also as being the cause of our perceiving it. Similarly in action, we do not just intend to achieve something, but intend it as the effect of our intending it. In each case, Searle calls this phenomenon "intentional causation." The selfreferentiality of these kinds of intentions packs causation into their conditions of satisfaction. Therefore, when the conditions of satisfaction are fulfilled (when action or perception is successful) causation is part of the content of the experience. It is important to stress that causation is part of the content of the experience, not its object. This brings Searle's position into close alignment with James and Whitehead. Causality will never turn up as an object of our experience, where Hume was looking for it.

Space prevents me from discussing a number of relevant questions, e.g., whether Searle has really succeeded in rebutting Hume's critique and how the common sense view of perception can be reconciled with its physiological explanation. It may be that on these points Whitehead has done a better job than Searle-and a better job than Pred's Jamesian interpretation of Whitehead allows for. But here I must pass on to Pred's illuminating discussion of why Searle's account of intentional causation is phenomenologically inadequate.

Because the key to Searle's analysis of intentional causation is the logical structure of its conditions of satisfaction, he tends to reduce intentional states to their propositional content, abstracting from the formation of those states in time. In the case of perception this leads him to treat its intentionality as something we can understand based on the structure it has at an instant (pp. 57, 72). In the case of action, it leads him to focus on what analytic philosophers call "basic actions" (pp. 74ff.), which are defined as actions (like raising your arm) that are not performed by means of other actions. Firing a gun, for example, is not basic because it is done by means of pulling the trigger, which is itself an intended action. But because the things by means of which pulling is effected (e.g., efferent nerve activity) are not 
themselves intended actions, pulling is basic. Pred points out that this approach takes what is essentially a fiction as the unit of analysis: we never perform basic actions, like raising our arms, for their own sake (p. 75). Examining the conditions of satisfaction of a purposeless basic action, as Searle does, yields a false analysis of the experience of acting. What gets left out is precisely the way a transition is made from a decision to perform a non-basic action to its mediated consummation. Pred rightly insists that a critical part of the intervening steps-most of the ones that would actually qualify as "basic actions" - are executed semi-automatically by habituated routines and competencies encoded in body memory (pp. 37, 76f., 82ff.). The crucial point is that unless we are actually in the process of learning a completely new skill, our actions are never performed by willing their basic components (pp. 37, 39, 40, 42). The latter are executed by a concatenation of acquired reflexes, the perceived consummation of each eliciting the next until we arrive at a node where the intervention of direct attention is required. From this Pred concludes that the transitive parts are precisely the workings of habit (pp. 36-48, 53).

It is interesting to see how his analysis is borne out even in the case of perception. Perception always takes place in the context of a personal activity situation in which we are pursuing more or less proximate goals. The situation and the goals that define it can be as trivial and mundane as you like, but they are never absent, and this gives the stream of experience what James calls a dramatic shape-a feeling of purpose exercised against felt obstacles (pp. 43ff., 46ff., 75, 114ff.). Pred emphasizes that perception is normally subservient to these goals, indicating the success or failure of an action at its termination and, during its execution, functioning as a monitor on the workings of habit, alerting us when their execution does not proceed smoothly toward the intended goal (pp. 39-48, 82ff., 99ff., 103, 108-13, 223240). But to drive his point home, Pred is willing to take as an example the case that should be least amenable to his analysis: a perception with a purely cognitive motivation (pp. 72f., 87ff., 93f., 113ff.). Even here we find that perception is not purely passive, but contains an essential actional component. Suppose we are not pursuing a goal, but simply want to see what something is that has caught our attention from the periphery of our field of vision. This seeing means looking, which already involves changes of posture and visual focusing. These are activities whose appropriate execution must be learned, and while they may be simple activities compared to others, they are nevertheless quite complex, as anyone knows who has to relearn them after stroke-related paralysis. The intention to see thus triggers a complex chain of activities involving habituated know-how. Treating perception as something purely passive makes it seem like something without an actional component or temporal thickness. 
Now it is not the case that Searle ignores non-basic actions, for although he does not take them as his analytic paradigm for understanding intentionality, he nevertheless discusses them in connection with the transitivity of causation: I can intend to cause y (e.g., firing the gun) by causing $\mathrm{x}$ (pulling the trigger), which causes $\mathrm{y}$ directly. Because causation is "transitive" I cause y as much as x. With this analysis Pred can elucidate what James calls the co-conscious transition. Where the execution of habitual know-how is the proximate actional means, transitive causation is a habitmediated transition between buds of consciousness where the same substantive part functions in each bud, first as the intent to be satisfied and then as the satisfied intent (pp. 55, 117). This is precisely a co-conscious transition. For example, we reflexively pull the trigger when we decide to fire the gun, and this learned habit causally mediates the transition between a bud in which something is intended but not yet consummated and a bud in which the same intention is perceived to be consummated.

While it is James' phenomenology that Pred accords a canonical status, he finds his neuro-physiological speculations an irresistible expository tool (pp. $22,24,27,28,30-3,36-40$ ). James' postulate of psycho-physical parallelism means that every phenomenological finding has a physical model. Pred is therefore able to corroborate his interpretation of James' phenomenology by showing how well it correlates with James' model of brain activity. In fact, Pred makes such liberal expository use of the physical model that the independence of his phenomenology from imagery associated with an empirical model of the brain can be called into question. This suspicion is acute in the case of the concept of habit that is so central to Pred's interpretation, for, as Pred knows, habit is not a phenomenological concept (p. 43). Habit is a concept acquired from the external observation of an organism's behavior. It is easy to understand habit on James' physical model of the brain as an organ of "plasticity." In the connectivity of the brain's neural net associative connections are formed with each experience. After they are formed, these connections tend to persist even as they constantly undergo incremental change due to new associations (pp. 33, 37f.). This model allows us to think of habit and body memory as a kind of physical inertia (p. 107). But this is a non-phenomenological account that presupposes psycho-physical dualism. If we rigorously limit ourselves to phenomenology (which Pred himself construes as an experiential monism (pp. 50ff.)), can we appeal to habit at all? What is the phenomenological counterpart to what we objectively describe as habit? Pred's answer is disappointing: subjective feelings of tendency and direction (p. 44). It's hard to see how feelings of tendency and direction can do anything. What is missing is the power of causal efficacy that makes Pred's habit-based model of intentional causality work. Pred needs to relinquish phenomenology or 
develop a richer kind of phenomenology (as Whitehead arguably tried to do), but as it stands his phenomenology is inconsistent.

\section{Systematic Correlations between James, Searle, Whitehead, and Edelman}

With this much of Pred's Jamesian model of intentionality on display, we can appreciate some of the many remarkable correlations he draws. Searle shows that an intentional state has specifiable conditions of satisfaction only a) in the context of other intentional states and b) against a background of unconscious dispositional knowledge of both how things are in the world and how to do things. The conditions of satisfaction of an intentional state correspond to the core of a Jamesian substantive part (p. 62), while Searle's network corresponds to the fringe (pp. 68ff.). Searle's background correlates well with James' concept of the self (pp. 59, 62ff.), which, in the form of the $\mathrm{Me}$, represents the totality of an individual's accumulated dispositions. Since it is an activated part of the Me that functions transitively in James' coconscious transition, its correlation with Searle's background suggests a correspondingly more active role for the background than Searle's account of it allows (pp. 63, 118). The passivity of Searle's background is the flip side of his neglecting the habit-mediated actional component of intentionality.

Turning to Whitehead, Pred relates perception in the mode of causal efficacy with the pre-intentional awareness by which we are vaguely (and still only passively) aware of items in the perceptual fringe, while perception in the mode of presentational immediacy corresponds to the actionally mediated intentional perception which brings such items into focus as substantive parts (pp. 189-99). Whitehead's eternal objects are naturalized as James' concepts, experientially acquired and dispositionally available ways of recognizing substantive parts, and their status as possibilities and lures for feeling is preserved insofar as they are, however faintly, present in the fringe (pp. 171-179). In a sense the fringe is never really less than the whole of the Me, for even subliminal dispositions contribute incrementally to the global summation that makes each bud unique even when its substantive topic is common to other buds (pp. 23ff., 30-33, 37ff.). The correspondence between Whitehead's concrescence and the transitive parts within a bud is straightforward, as is the correlation of co-conscious transition between buds with "superjection" (p. 218). But it comes as something of a surprise to find that Pred has constructed a model that allows him to make good sense of one of Whitehead's more abstruse metaphysical creations: the hybrid physical prehension (pp. 151f., 25ff.). The most important example of the hybrid physical prehension, Pred argues, is an occasion's prehension of its own immediate predecessors in a personally ordered society of occasions, 
and as such it is nothing other than the co-conscious transition: I physically prehend my immediately preceding physical state, but through it I prehend the concepts it was prehending mentally. In this way there can be the sort of continuity of purpose characteristic of habit-mediated intentional causation, where a mental resolve is not re-enacted with each moment of its execution, but borne along physically by the habitual behavior it sets off.

Without going into details, I note a few of the correlations that result from Pred's mapping of Whitehead onto Edelman: the remembered present and the bud, reentry and contrasts, expectancies and subjective aims, perceptual bootstrapping and hybrid physical prehensions (pp. 283ff.). While not committing himself to this particular neurobiological account of consciousness, Pred wants to show that an extremely tight fit between Whiteheadian and neurobiological concepts is possible. Pred is going for an unexpectedly strong conclusion, however. For if Whitehead has in fact overcome phycho-physical dualism with his categorial scheme, then a neurobiological model that realized his scheme would amount to a nondualistic neurobiology. Although Edelman thinks of himself as a scientific materialist, Pred suggests that he may have overcome the limitations implied by this commitment and provided a theory of consciousness amenable to a neutral monism (pp. 282, 300ff.).

\section{A Metaphysical Bias in Edelman's Theory of Consciousness and a Whiteheadian Critical Theory}

In a final dazzling gesture that ties together many of the themes of his book, Pred points to a serious weakness in Edelman's account of higher consciousness. According to Edelman higher consciousness depends on the symbolic modeling of the self-nonself distinction, and hence on language (pp. 267ff.). But central to the emergence of a grammar rich enough to model the self-nonself distinction is, he believes, the development of a rich subjectpredicate relation (p. 269). But Edelman is here operating under limitations imposed by an unrecognized bias. For he is taking as essential to language the grammar of modern Indoeuropean languages, in which unilateral transitivity is the paradigmatic way of relating subject to predicate (p. 269). This is evident in the fact that these languages have two voices, the active and passive, which are complementary ways of expressing the same relation of unilateral transaction. But some ancient languages, Sanskrit and archaic Greek, for example, had a third voice, which grammarians call the "middle voice" - middle because it is neither active nor passive, but something in between, where the subject of the verb both acts and is affected by his acting 
(pp. 274ff.). This is a phenomenon of language to which Heidegger drew attention. It suggests a way of parsing experience that is not locked into the sort of categories familiar to us at least since the philosophy of Aristotle: substance, quality, action, passion. In a middle-voice based language, the self-nonself distinction could be neither absolute nor fundamental. Whatever one thinks of Heidegger's philology-based "history of being," Pred is right that Edelman's concept of consciousness is unjustifiably narrow. There is no obvious reason why a higher consciousness derived from a middle-voiced form of language should be impossible, and the analysis of consciousness Pred derives from James and Whitehead suggests that such consciousness may actually be more fundamental: experience is something that comes together through a process of mutually influencing and accommodating elements (pp. 276-82). This process necessarily seems vague to critical analysis precisely because it cannot be factored into units of simple action and passion, enacted along a linear chronology among discrete agents and patients and resulting in effects predictable in advance (p. 281). What Whitehead calls concrescence is essentially a middle-voice phenomenon.

Although we would not normally think of Whitehead as a "critical social theorist," it is nevertheless true that he advanced a trenchant critique of the modern world. He was exercised by what he saw as the malignant role played by the concept of substance in the history of the west-not just in philosophy, but also in the development of ethical ideas and social institutions. Substance was traditionally defined as something that needs nothing else in order to exist, and this implies that it is impassive. It could be an agent, but it could not be affected by its own actions. Substance, in other words, is what functions as the subject of transitive verbs in the active voice. Pred suggests that the objectifying attitude characteristic of western thinking, which phenomenology strives so hard to overcome, is a function of "active-voice withdrawal" (pp. 19, 276ff.). Things become the objects of "observation" precisely when the thinker becomes impassive in relation to them. With his philosophical analysis of the differences between the middle and active voices, Pred adds clarity and a layer of depth to some of Whitehead's central concerns: "mind-body and related dualisms can be regarded as outgrowths of the unwitting decision to let active-voiced-based language games establish boundary conditions for rational discourse" ( $p$. 278).

No phenomenologist or critical theorist can fail to find these observations profound. The loss of the middle voice is indeed the loss of a grammar for a way of being and experiencing being that is not defined by relations of exclusion and hegemony. The ascendancy of unilateral transitivity, which is characteristic of the active and passive voices, is precisely what Continental philosophers have been calling the age of "metaphysics." Because they believe that unilateral transitivity as a way of thinking goes along with 
unilateral transitivity as a way of ordering social relations, they see the "end of metaphysics" as social emancipation. The discourse of the (selfappointed) post-metaphysicians is often self-involved and pretentious. There is no reason to excuse this, but there is nevertheless a reason for it. While it is very easy to go on about what post-metaphysical thinking is not and thus fall back into a discourse of exclusivity and superiority (which they often do), it is very difficult (intrinsically difficult? impossible?) to say what post-metaphysical thinking is, and attempts to do so inevitably get caught up in themselves in ways that, say, an ethics more geometrico need not. But we cannot afford to dismiss their project, for the stakes are not merely theoretical. It concerns the conditions of the possibility of democracy and the meaning of pluralism and toleration in a multi-cultural society. The problem is especially acute now that the globe is no longer home to multiple nonoverlapping societies, but covered instead by a single society in which disparate cultures are superposed.

Pred's plainspoken reflections on a metaphysics of the middle voice are therefore timely and all the more valuable because they are plainspoken and do not fall prey to the post-modern dilemma of having to choose between a discourse that is self-important (heroically overcoming the whole bad tradition) and one that is self-destructive (fleeing its own self-importance). At the same time he reveals remarkable affinities between Whitehead, the metaphysician, and the Heideggerian project of post-metaphysical thinking. Granted, there is no little irony in a metaphysical grounding of postmetaphysical thinking, to say nothing of grounding it in —of all things!-a theory of subjectivity. One can anticipate the smugness of some postmetaphysicians, who will show us that they are right again by deconstructing Pred's argument as a predictable attempt by metaphysics to appropriate and thus to subjugate its "other." But isn't this precisely the kind of master-thinking that dominates by refusing the other the right to be heard? Pred's book, on the other hand, is a remarkable example of a discourse whose own legitimacy is not predicated on delegitimating alternative kinds of discourse. Instead he opens the possibility of constructive dialogue among disciplines and intellectual orientations that have long been strangers or antagonists: metaphysics, post-metaphysical thinking, phenomenology, cognitive psychology, and experimental neurobiology. And isn't this a better example of the "weak thought" Vattimo has called for than a critical theory that has insulated itself from critique by defining its other as bad faith? It does seem odd that postmodern thought bridles at difference and seeks to limit the forms that discourse can take. Is there nothing to be learned from a serious attempt to think subjectivity "non-metaphysically"? In a Feyerabendian spirit, shouldn't robustly adventurous thought experiments of the type Pred offers 
us be encouraged? Don't we stand to benefit from their multiplication, rather than their limitation?

\section{Final Doubts about Pred's Faith in Phenomenology}

In regard to the book's phenomenological ambitions I think Pred's own brilliance finally does him in. Even a great number of Continentally oriented philosophers, who are most invested in this sort of thing (the "house" of Being's lost structures that are still evident in archaic language), have never heard of the middle voice. But what does that mean-that they haven't done enough homework? No, I think the lesson is chastening to us all. No amount is ever "enough," and this has implications for Pred's project and for phenomenology in general. It's a little bit as though we were a linguistic community that had never heard of meter, and someone comes along and tells us we've been speaking prose all our lives. If only we had known, we could have opted for poetry! Now comes a philosopher-linguist, tells us we have been speaking in the voice of unilateral transitivity all our lives. Who knew? But, as it turns out, the result of our ignorance is that our perception of ourselves and of the world, even our very attempts to do phenomenology, have been skewed. But isn't this just the kind of invisible dependency of appearance on language that Rorty and others inspired by Wittgenstein are talking about?

Pred's acuity in exposing a latent linguistic bias in what phenomenologists-including Whitehead in his relevant attemptsconfidently thought were description beholden to nothing but "raw, unverbalized data" casts a dark shadow on his own confidence at having gotten beyond language to "appearances in themselves." The middle voice was important in Sanskrit and disappeared with ancient Greek. But what linguistic possibilities were lost already with the disappearance of protoIndoeuropean? For all we know there may be still earlier, barely imaginable language types (a common ancestor of inflected and isolative languages?) that harbor apophantic possibilities inconceivable to us and the loss of which has left us forever speaking prose and mistaking it for the poetry of Being.

\section{Notes}

${ }^{1}$ New York. 
${ }^{2}$ Ralph Pred, Onflow. Dynamics of Consciousness and Experience, London and Cambridge, The Massachusetts Institute of Technology Press, 2005. 